\title{
W poszukiwaniu istoty empatii. Wnioski z przeglądu badań neuronaukowych i ich praktyczne implikacje
}

\section{The essence of empathy: a review of the neuroscience research and its applications}

\begin{abstract}
Empathy, subjected to personal differences, is a key to a functional social life. In recent years neuroscience has contributed to the precise terminology and methodological approach in the research of empathy, mainly due to development of non-invasive brain imaging techniques. The article presents a literature review and aims to determine the areas of neuroscience which help to understand empathy. Attention is drawn to role of the research in determining parts of brain responsible for different types of empathy (cognitive and emotional). The research also shows that there are modulators of emphatic response and hence practical applications of knowledge may be possible in the therapy of maladaptive forms of empathy (e.g. personal distress).
\end{abstract}

Keywords: emotional empathy, cognitive empathy, personal distress, empathy modulation

\section{Wprowadzenie}

Empatia to iskra ludzkiej troski, klej umożliwiający istnienie życia społecznego tak zjawisko empatii określa Hoffman [2000]. Baron-Cohen [2014] uważa nawet, że empatia jest najważniejszym zasobem naszego świata. W XX wieku ogromnie wzrosło zainteresowanie fenomenem, który w przypadku gatunku ludzkiego osiągnął tak zaawansowany poziom. Jego skomplikowany charakter skłania badaczy do interdyscyplinarnego podejścia do problemu. Coraz częściej złożoność zachowań organizmów żywych bada się poprzez próbę wyjaśnienia funkcji aktywności mózgu. Naukowcy znajdują nowe połączenia między emocjami i rozumem, zachowaniem i percepcją, między reprezentacją otaczających nas ludzi i reprezentacją nas samych - wspólnie działają na gruncie neuronauki społecznej [Adolphs, 2003]. Analiza aktywności mózgu podczas empatyzowania pozwala badaczom uporządkować intuicje towarzyszące ludziom od wieków. Dzięki technikom neuroobrazowania możemy ustalić, jakie są mózgowe podstawy empatii, zidentyfikować modulatory zachowań empatycznych 
[np. de Vignemont i Singer, 2006], a także starać się odpowiedzieć na pytanie, co jest przyczyną deficytów empatii. Jak pisze Howe [2013, s. 55], „Neurobiologia pomaga zrozumieć naszą zdolność do empatii, a doświadczenie empatii wskazuje neurobiologom to, jak powinni badać subtelności i zawiłości naszego społecznego mózgu”.

W artykule przyjęto rozumienie empatii jako zdolności wykazującej zróżnicowanie indywidualne. Dokonano przeglądu niektórych doniesień naukowców zajmujących się zagadnieniem empatii, które $\mathrm{w}$ znacznym stopniu przyczyniają się do budowania jednolitej ramy teoretycznej do dalszych badań. Dokonania te pozwalają również tworzyć precyzyjne definicje oraz konstruować adekwatne modele procesu empatii, wskazują na mózgowe podstawy zjawisk często podobnych na poziomie obserwacji, jednak różniących się neuronalnymi podstawami. Następnie przedstawiono możliwości praktycznego zastosowania gromadzonej wiedzy. Czy możliwe jest trenowanie kompetencji związanych $\mathrm{z}$ empatią?

\section{Niedostępne gołym okiem. Wpływ wyników badań neuronaukowych na definiowanie zjawiska empatii}

Pojęcie empatii ma swoje korzenie w filozofii estetyki. Niemieckiego terminu „Einfühlung” użył Robert Vischer [1873/1994], aby opisać przyjemność, która jest związana z kontemplacją dzieła sztuki. Na początku XX wieku naukowcy zaczęli adaptować termin „empatia” do nauk społecznych na gruncie prób zrozumienia ludzkich doświadczeń z subiektywnego punktu widzenia. W tym czasie Theodor Lipps [1903/1979] wykazał się genialną intuicją, postulując, że obserwowanie cudzego stanu emocjonalnego powoduje $u$ obserwatora wystąpienie stanu wewnętrznej imitacji. $\mathrm{O}$ trafności intuicji Lippsa świadczą przełomowe wyniki badań z końca XX wieku dotyczące odkrycia neuronów lustrzanych. Neurony te aktywują się zarówno wtedy, gdy ktoś wykonuje daną czynność, jak i w momencie, gdy obserwuje inną osobę wykonującą tę czynność [Mukamel i in., 2010; Rizzolatti i in., 1996]. Wydaje się, że na bardzo podstawowym poziomie mózg nie odróżnia własnego działania od działań „innego".

\subsection{Pytanie o strukturę empatii}

Pojęcie empatii jest złożone i potocznie używane do określania zjawisk podobnych, ale nie tożsamych. Problemy definicyjne skupiają się głównie wokół kwestii, czy empatia jest rozumieniem czyichś stanów emocjonalnych (jeśli tak, to czym jest owo „rozumienie”), czy może zachodzi już na etapie automatycznego doświadczania emocji innych ludzi. Ten konflikt można ująć również jako próbę określenia struktury i specyfiki empatii, to znaczy należy odpowiedzieć na pytanie, czy empatia ma charakter poznawczy, emocjonalny, czy też jest konstruktem składającym się z dwóch wymienionych aspektów. Współcześnie przyjmuje się, że empatia jest zjawiskiem co najmniej dwukomponentowym.

Emocjonalny aspekt empatii przejawia się w zjawiskach takich jak: dzielenie afektywnego pobudzenia, zarażanie emocjami, dzielenie bólu [Shamay-Tsoory, 2011]. 
Howe [2013] nazywa empatię emocjonalną empatią ucieleśnioną, która zachodzi bez refleksji czy świadomej myśli. Noworodki kilka godzin po urodzeniu naśladują wyrazy mimiczne twarzy, takie jak otwieranie ust, wysuwanie języka [Meltzoff i Moore, 1983]. Niemowlęta przejawiają reakcję reaktywnego płaczu, kiedy słyszą płacz innych dzieci [Hoffman, 2006]. Innym przykładem zachowania empatycznego opartego na komponencie afektywnym jest tzw. zarażanie emocjonalne - rodzaj dzielenia afektu. Zarażanie emocjonalne następuje wtedy, gdy stan afektywny danej osoby jest wynikiem percepcji stanu afektywnego innej jednostki [Hatfield, Cacioppo i Rapson, 1994]. Zarażanie emocjonalne i nieświadoma mimikra pomagają koordynować zachowanie i emocje między partnerami w interakcji i komunikacji [Bavelas i in., 1996]. Osoby wykazujące wyższy poziom spontanicznej imitacji i afektywnego rezonansu zdobywają więcej punktów na skali samoopisującej zachowania empatyczne [Chartrand i Bargh, 1999], a więc prawdopodobnie empatia emocjonalna stanowi przynajmniej po części o ogólnej zdolności człowieka do empatyzowania. Jednocześnie wymienione zjawiska wskazują na fakt, że empatia emocjonalna obejmuje raczej automatyczne, bardziej pierwotne formy współodczuwania. Szczególnie dane z zakresu psychologii rozwojowej świadczą o potrzebie uwzględnienia poznawczego rozwoju człowieka, który umożliwia kompleksowe rozumienie stanu drugiej osoby, aby w pełni analizować zjawisko empatii.

Poznawczy aspekt empatii wiąże się ze złożonymi procesami, takimi jak przyjmowanie czyjejś perspektywy lub wyobrażanie sobie tego, jak czuje się inna osoba w danej sytuacji [np. Lamm, Batson i Decety, 2007]. Test fałszywych przekonań, który jest uznawany za dowód na wykształcenie teorii umysłu, dzieci przechodzą dopiero około czwartego roku życia (w zależności od konstrukcji testu) [Baron-Cohen, Leslie i Frith, 1985; Wimmer i Perner, 1983]. Z badań nad teorią umysłu wynika, że przed ukończeniem czwartego roku życia dzieci nie rozumieją w pełni, że istnieją różnice między ich własnymi treściami mentalnymi a treściami innych ludzi. Co prawda, niektóre badania dowodzą, że na wcześniejszych etapach życia dzieci radzą sobie z testami np. w wersji niewerbalnej [Scott i Baillargeon, 2009], jednak jest jasne, iż bardziej wysublimowane przejawy empatii (umiejętność przyjmowania i rozumienia perspektywy drugiej osoby) wymagają rozwoju kompetencji poznawczych. Po pierwsze, istotny jest rozwój systemu uwagi, który pozwala na budowanie reprezentacji triadycznych (tzn.: ja - ty - obiekt). Wspólna uwaga jest rewolucją w rozwoju społecznym dziecka, bo wtedy dzieci zaczynają rozumieć, że inni ludzie są intencjonalnymi podmiotami, tak jak one same [Tomasello, 2002]. Po drugie, niezbędny jest pewien poziom samoświadomości, czyli rozpoznanie, że jest się odrębnym, intencjonalnym podmiotem [Lewis i Brooks-Gunn, 1979]. Po trzecie, szczególnie ważnymi kompetencjami poznawczymi, jakie muszą się wykształcić w celu osiągnięcia teorii umysłu, są funkcje wykonawcze, takie jak planowanie, a zwłaszcza kontrola i hamowanie zachowań.

Badanie mózgowego podłoża empatii jest odpowiedzią na wątpliwości dotyczące struktury empatii. Wyniki wskazujące na odmienne neuronalne wzorce aktywności dostarczają solidnych podstaw do różnicowania afektywnych i poznawczych przejawów empatii. Doskonałym przykładem badań popierających tę tezę są doniesienia Shamay-Tsoory, Aharon-Peretz i Perry [2009]. Dzięki studium przypadków pacjentów z lezjami określonych obszarów badacze wskazali na odrębne rejony kluczowe 
dla prawidłowego funkcjonowania empatii emocjonalnej (dolny zakręt czołowy, ang. Inferior Frontal Gyrus, IFG) i poznawczej (brzuszno-przyśrodkowa kora przedczołowa, ang. ventromedial Prefrontal Cortex, vmPFC). Bardziej szczegółowa analiza uszkodzeń wykazała, że pole 44 Brodmanna jest kluczowe dla empatii emocjonalnej, natomiast pola $10 \mathrm{i} 11$ są istotne dla empatii poznawczej. Co ważne, pole 44 Brodmanna jest uznawane za „siedlisko" neuronów lustrzanych. Analiza lezji vmPFC i IFG stanowi ważny, bezpośredni dowód dysocjacji dwóch rodzajów empatii. Co więcej, wskazane rejony różnią się swoją cytoarchitekturą. W budowie histologicznej pól 10 i 11 Brodmanna występują warstwy ziarniste w przeciwieństwie do pola 44 [Brodmann, 1909/2006], co stanowi pośredni dowód, że obszar 44 jest starszy filogenetycznie niż obszary 10 i 11 [Shamay-Tsoory, Aharon-Peretz i Perry, 2009]. Analiza anatomii struktur mózgowych wskazuje na bardziej pierwotny charakter empatii emocjonalnej, co jest spójne z doniesieniami z psychologii rozwojowej. Przywołane badania stanowią doskonały przykład tego, jak dane z zakresu neuronauk mogą wzbogacać i porządkować dotychczas gromadzoną wiedzę.

\section{Współcierpienie czy współczucie? Modulowanie odpowiedzi empatycznego mózgu na czyjeś cierpienie}

Ból jest nieprzyjemnym wrażeniem zmysłowym wywołanym przez szkodliwy dla organizmu bodziec. To ważny sygnał oznaczający, że zdarzyło się coś, co może stanowić zagrożenie dla życia lub przetrwania w dłuższej perspektywie czasowej. Informacje bólowe mają kluczowe znaczenie dla podtrzymania dobrostanu organizmu, dlatego też jesteśmy szczególnie wyczuleni na oznaki odczuwania bólu wyrażane przez innych ludzi, co znalazło zastosowanie w badaniu mózgowych podstaw empatii.

\subsection{Skutki obserwacji cierpienia innych}

Większość badań nad zjawiskiem empatii wykorzystuje paradygmat, w którym to badani obserwują sytuację doświadczania bólu przez inną osobę w celu wywołania u nich odpowiedzi empatycznej mózgu [np. de Vignemont i Singer 2006; Decety i Lamm, 2006]. Analiza aktywności mózgu obserwatora daje możliwość badania neuronalnego podłoża empatii. Przełomowym badaniem w tym paradygmacie był eksperyment Tani Singer i współpracowników [2004]. Podczas empatyzowania z osobą doznającą bólu dochodzi do aktywacji części matrycy bólowej, czyli obszaru normalnie zaangażowanego w odczuwanie realnego bólu. Zaobserwowano aktywację rejonów związaną jedynie z afektywnymi składowymi bólu, a mianowicie przedniej części kory wyspy i przedniej części zakrętu obręczy. W porównaniu z sytuacją realnego doświadczania bodźca bólowego nie dochodziło do pobudzenia tej części matrycy bólowej, która odpowiada za komponent sensoryczny.

Wzajemne pokrywanie się obwodów neuronalnych w opisanych powyżej sytuacjach może prowadzić do poczucia osobistej przykrości, a ta z kolei może powodować egoistyczne motywacje do działania w celu redukcji negatywnego napięcia [Decety i Lamm, 2009] i zmniejszać prawdopodobieństwo zachowań prospołecznych [Tice, 
Bratslavsky i Baumeister, 2001]. Spektrum odczuć wywołanych przez percepcję czyjegoś cierpienia rozciąga się od współczucia i troski po strach, niepokój i unikanie. Decety, Yang i Cheng [2010] zwrócili uwagę na fakt, że regulacja odpowiedzi empatycznej jest szczególnie ważna w przypadku osób, których profesja wiąże się z częstym obserwowaniem ludzkiego cierpienia, czy też z koniecznością zadawania bólu, jak dzieje się to na przykład w zawodzie lekarza. Brak tej umiejętności może skutkować wypaleniem zawodowym albo zanikiem współczucia.

Badania prowadzone przez Eisenberg i współpracowników [Eisenberg i in., 1994; Eisenberg, Fabes i Spinrad, 2006] wykazały, że istnieją indywidualne różnice w tendencji do doświadczania sympatii (rozumianej jako poczucie troski wobec kogoś) a odczuwania osobistej przykrości. Źródłem takiego stanu rzeczy są indywidualne zdolności do regulacji emocji. Dojrzała i adaptacyjna forma empatii odznacza się umiejętnością modulowania doznawanych negatywnych emocji w celu utrzymania optymalnego poziomu pobudzenia emocjonalnego [Decety i Michalska, 2010]. Zagadnieniem wartym starannej analizy jest możliwość stosowania terapii nieadaptacyjnych form współodczuwania, które charakteryzują się negatywnym pobudzeniem obserwatora czyjegoś cierpienia. $Z$ tego punktu widzenia bardzo ważne są doniesienia wskazujące na istnienie modulatorów reakcji empatycznej.

\subsection{Badania nad czynnikami modulującymi empatię}

Jak pokazują wyniki badań, istnieje wiele czynników będących modulatorami empatii. Mają one charakter zarówno osobniczy, relacyjny, jak i sytuacyjny. Aktywność części matrycy bólowej w odpowiedzi na obserwacje bólu innych pojawia się nie tylko wtedy, gdy cierpi ktoś nam bliski [Singer i in., 2004], ale także gdy bólu doświadcza ktoś obcy [Botvinick i in., 2005]. Również prezentacja samej ręki nakłuwanej igłą powoduje odpowiedź empatyczną w mózgu [Morrison i in., 2004). Te wyniki sugerują, że empatyzowanie zachodzi automatycznie w odpowiedzi na emocje innych. Z drugiej jednak strony można wskazać na badania świadczące o wpływie kontekstu sytuacyjnego oraz innych czynników modulujących odpowiedź empatyczną. Wśród modulatorów wymienia się intensywność bodźca (ból ostry versus ból chroniczny) [Saarela i in., 2007]. Im stymulacja bólowa była większa lub ekspresja twarzy cierpiącego wyraźniejsza, tym wyższy obserwowano stopień pobudzenia obszarów mózgu zaangażowanych w empatię bólu [Hein i Singer, 2008]. Innym modulatorem jest bliskość relacji między obserwatorem a cierpiącym [Singer i in., 2006]. Na znaczenie kontekstu sytuacyjnego wskazał Lamm ze współpracownikami [2007]. Badani, których poinformowano, że cierpienie, jakiego doznaje osoba słuchająca nieprzyjemnych dźwięków, jest częścią terapii defektów słuchu, wykazywali niższą aktywność przedniej części zakrętu obręczy i przedniej części wyspy. Również procesy uwagowe nie pozostają bez znaczenia. W grupie badanych, w której poproszono o liczenie prezentowanych rąk, co odwracało ich uwagę od sytuacji bólowej, aktywność „empatycznego mózgu” była mniejsza niż w grupie bez dodatkowego polecenia (Gu i Han, 2007).

Powyższe wyniki sugerują, że istnieje możliwość wpływania na odpowiedź empatyczną mózgu. Taki wniosek motywuje do zgłębiania kwestii możliwej terapii osób szczególnie narażonych na negatywne skutki obcowania z cierpieniem oraz przypadków przejawiania nieadaptacyjnych form współodczuwania. 


\subsection{Trening adaptacyjnego współczucia}

Niezwykle ciekawe badania autorstwa Klimecki, Leiberg, Ricarda i Singer [2014] dotyczą wpływu treningu współczucia na aktywność mózgu. Punktem wyjścia jest stwierdzenie, że mimo iż empatia jest kluczowa dla pozytywnych interakcji społecznych, negatywne emocje związane z percepcją cierpienia innych osób mogą być nieadaptacyjne i szkodliwe. Opracowano trening empatii opierający się na tzw. przyjmowaniu perspektywy zorientowanej na siebie. Jedna z grup badanych wzięła udział najpierw w treningu empatycznego rezonansu, a później w treningu współczucia, natomiast grupa kontrolna przeszła przez trening pamięci. Po treningu empatii (ale nie po treningu pamięci) zaobserwowano znaczny wzrost negatywnego afektu i wzrost aktywności w korze wyspy i korze zakrętu obręczy. W następstwie odbycia treningu współczucia efekt był odwrotny, to znaczy badani raportowali pozytywne odczucia w odpowiedzi na materiał filmowy. Trening współczucia wpłynął na redukcję aktywności kory wyspy i kory zakrętu obręczy oraz na wzrost aktywności brzusznej części prążkowia i kory nadoczodołowej (struktur związanych z przeżywaniem nagrody). Autorzy zauważyli, że empatia może być nieadaptacyjna w przeciwieństwie do współczucia. Na podstawie wyników wyciągnęli wniosek, że trening współczucia może być nową strategią przezwyciężania osobistej przykrości oraz wzmacniania odporności na negatywne doznania związane $\mathrm{z}$ współodczuwaniem cierpienia. $\mathrm{Z}$ pewnością jest to perspektywa warta rozwijania, jako że może mieć praktyczne zastosowanie w terapii oraz we wspomaganiu osób, których praca wymaga obcowania $\mathrm{z}$ cierpieniem innych. Co ważne, $\mathrm{w}$ porównaniu $\mathrm{z}$ innymi strategiami regulacji, trening współczucia nie opiera się na zaprzeczaniu cierpienia drugiego człowieka. Prawidłowa forma współodczuwania przynosi korzyści zarówno obserwatorowi, jak i potencjalnie cierpiące$\mathrm{mu}$, jako że motywuje do pomagania i innych zachowań prospołecznych [Leiberg, Klimecki i Singer, 2011].

Badania sugerujące istnienie czynników modulujących empatię wskazują również na jej dużą plastyczność, pomimo wielu argumentów postulujących jej automatyczny charakter. Warto szczegółowo badać czynniki modulujące, aby odpowiedzieć na pytania: czy różnice indywidualne w poziomie empatii mogą być tłumaczone przez stałe cechy osobowości oraz w jakiej relacji pozostaje empatia do zachowań prospołecznych?

\section{Wnioski}

Ewolucyjna historia zdolności do empatyzowania jest długa, czego zdecydowanie nie można powiedzieć o tradycji badania tego zjawiska. Chociażby krótka historia terminu „empatia” uświadamia nam, jak niewiele uwagi poświęcano temu zagadnieniu. $\mathrm{W}$ ostatnich latach ta tendencja odwróciła się i można mówić o prawdziwej eksplozji badań nad empatią. Szczególnie efektywne są prace badawcze neuronaukowców wskazujące na mózgowe procesy zaangażowane w empatyzowanie. Coraz lepsze zrozumienie tego zjawiska owocuje wiedzą, która $\mathrm{z}$ powodzeniem może być stosowana w praktyce. 


\section{BIBLIOGRAFIA}

Adolphs, R. (2003). Cognitive neuroscience of human social behaviour. Nature Reviews. Neuroscience, 4(3), 165-78.

Baron-Cohen, S. (2014). Teoria zła. O empatii i genezie okrucieństwa. Sopot: Smak Słów.

Baron-Cohen, S., Leslie, A.M., Frith, U. (1985). Does the autistic child have a "theory of mind"? Cognition, 21, 37-46.

Batson, C.D., Fultz, J., Schoenrade, P.A. (1987). Distress and empathy: two qualitatively distinct vicarious emotions with different motivational consequences. Journal of Personality, 55 (March), 19-39.

Bavelas, J.B., Black, A., Lemery, C.R., Mullett, J. (1986). "I show how you feel”: Motor mimicry as a communicative act. Journal of Personality and Social Psychology, 50(2), 322-329.

Botvinick, M., Jha, A.P., Bylsma, L.M., Fabian, S.A, Solomon, P.E., Prkachin, K.M. (2005). Viewing facial expressions of pain engages cortical areas involved in the direct experience of pain. NeuroImage, 25, 312-319.

Brodmann, K. (1909). Vergleichende Lokalisationslehre der Gro_hirnrinde. Leipzig, Germany: Johann Ambrosius Barth Verlag. Przekład angielski: Garey L.J. (2006). Localisation in the Cerebral Cortex. New York: Springer.

Chartrand, T.L., Bargh, J.A. (1999). The chameleon effect: the perception-behavior link and social interaction. Journal of Personality and Social Psychology, 76, 893-910.

de Vignemont, F., Singer, T. (2006). The empathic brain: how, when and why? Trends in Cognitive Sciences, 10(10), 435-441.

Decety, J., Lamm, C. (2006). Human empathy through the lens of social neuroscience. The Scientific World Journal, 6, 1146-1163.

Decety, J., Lamm, C. (2009). Empathy versus personal distress - recent evidence from social neuroscience. W: J. Decety, W. Ickes (Eds.), The Social Neuroscience of Empathy (s. 199-213). Cambridge: MIT Press.

Decety, J., Michalska, K.J. (2010). Neurodevelopmental changes in the circuits underlying empathy and sympathy from childhood to adulthood. Developmental Science, 13, 886-899.

Decety, J., Yang, C.Y., Cheng, Y. (2010). Physicians down-regulate their pain empathy response: An event-related brain potential study. NeuroImage, 50(4), 1676-1682.

Eisenberg, N., Fabes, R.A., Murphy, B., Karbon, M., Maszk, P., Smith, M., ... Suh, K. (1994). The relations of emotionality and regulation to dispositional and situational empathy-related responding. Journal of Personality and Social Psychology, 66, 776-797.

Eisenberg, N., Fabes, R.A., Spinrad, T.L. (2006). Prosocial behavior. W: N. Eisenberg (Vol. Ed.), W. Damon, R.M. Lerner (series eds.), Handbook of Child Psychology, Vol. 3: Social, emotional, and personality development (s. 646-718). New York: Wiley.

$\mathrm{Gu}, \mathrm{X}$., Han, S. (2007). Attention and reality constraints on the neural processes of empathy for pain. NeuroImage, 36, 256-267.

Hatfield, E., Cacioppo, J., Rapson, R. (1994). Emotional contagion. Cambridge: Cambridge University Press.

Hein, G., Singer, T. (2008). I feel how you feel but not always: the empathic brain and its modulation. Current Opinion in Neurobiology, 18, 153-158.

Hoffman, M. (2006). Empatia i rozwój moralny. Gdańsk: GWP.

Hoffman, M.L. (2000). Empathy, its arousal, and prosocial functioning. W: M.L. Hoffman, Empathy and Moral Development: Implications for Caring and Justice (s. 29-62). Cambridge: Cambridge University Press.

Howe, D. (2013). Empatia. Co to jest i dlaczego jest taka ważna. Warszawa: Oficyna Ingenium. 
Klimecki, O.M., Leiberg, S., Ricard, M., Singer, T. (2014). Differential pattern of functional brain plasticity after compassion and empathy training. Social Cognitive and Affective Neuroscience, 9, 873-879.

Lamm, C., Batson, C.D., Decety, J. (2007). The neural substrate of human empathy: Effects of perspective-taking and cognitive appraisal. Journal of Cognitive Neuroscience, 19, 42-58.

Leiberg, S., Klimecki, O., Singer, T. (2011). Short-term compassion training increases prosocial behavior in a newly developed prosocial game. PLoS ONE, 6(3).

Lewis, M., Brooks-Gunn, J. (1979). Social Cognition and the Acquisition of Self. New York: Plenum Press.

Lipps, T. (1903). Einfühlung, Inner Nachahmung, und Organempfindaungen. Archiv für gestame Psychologie, 1, 465-519. Przekład angielski: Empathy, inner imitation and sense-feelings. W: M. Rader (ed.) (1979), A Modern Book of Aesthetics. New York: Holt, Rinehart, Winston.

Meltzoff, A.N., Moore, M.K. (1983). Newborn infants imitate adult facial gestures. Child Development, 54, 702-709.

Morrison, I., Lloyd, D., di Pellegrino, G., Roberts, N. (2004). Vicarious responses to pain in anterior cingulate cortex: Is empathy a multisensory issue? Cognitive, Affective \& Behavioral Neuroscience, 4(2), 270-278.

Mukamel, R., Ekstrom, A.D., Kaplan, J., Iacoboni, M., Fried, I. (2010). Single-neuron responses in humans during execution and observation of actions. Current Biology, 20(8), 750-756.

Pinel, P. (1801). Abhandlung über Geisteverirrunger oder Manie. Wien, Austria: Carl Schanmberg.

Rizzolatti, G., Fadiga, L., Gallese, V., Fogassi, L. (1996). Premotor cortex and the recognition of motor actions. Cognitive Brain Research, 3(2), 131-141.

Saarela, M.V., Hlushchuk, Y., Williams, A.C., Schürmann, M., Kalso, E., Hari, R. (2007). The compassionate brain: Humans detect intensity of pain from another's face. Cerebral Cortex, 17 (January), 230-237.

Scott, R.M., Baillargeon, R. (2009). Which penguin is this? Attributing false beliefs about object identity at 18 months. Child Development, 80, 1172-1196.

Shamay-Tsoory, S.G. (2009). Empathic processing: Its cognitive and affective dimensions and neuroanatomical basis. W: J. Decety, W. Ickes (eds.), The Social Neuroscience of Empathy (s. 215-232). Cambridge: MIT Press.

Shamay-Tsoory, S.G. (2011). The neural bases for empathy. The Neuroscientist: A Review Journal Bringing Neurobiology, Neurology and Psychiatry, 17, 18-24.

Shamay-Tsoory, S.G., Aharon-Peretz, J., Perry, D. (2009). Two systems for empathy: A double dissociation between emotional and cognitive empathy in inferior frontal gyrus versus ventromedial prefrontal lesions. Brain, 132(2008), 617-627.

Singer, T., Seymour, B., O’Doherty, J., Kaube, H., Dolan, R.J., Frith, C.D. (2004). Empathy for pain involves the affective but not sensory components of pain. Science (New York, N.Y.), 303, 1157-1162.

Singer, T., Seymour, B., O’Doherty, J.P., Stephan, K.E., Dolan, R.J., Frith, C.D. (2006). Empathic neural responses are modulated by the perceived fairness of others. Nature, 439 (January), 466-469.

Tice, D.M., Bratslavsky, E., Baumeister, R.F. (2001). Emotional distress regulation takes precedence over impulse control: If you feel bad, do it! Journal of Personality and Social Psychology, 80(1), 53-67.

Tomasello, M. (2002). Kulturowe źródła ludzkiego poznawania. Warszawa: Państwowy Instytut Wydawniczy.

Vischer, R. (1873/1994). On the optical sense of form: A contribution to aesthetics. W: H.F. Mallgrave (ed.). Empathy, Form and Space. Los Angeles: Getty Center for the History of Art and the Humanities.

Wimmer, H., Perner, J. (1983). Beliefs about beliefs: Representation and constraining function of wrong beliefs in young children's understanding of deception. Cognition, 13, 103-128. 